https://journal.uwgm.ac.id/index.php/abdimasmahakam

Juni 2019, Vol. 3 No. 02

\begin{tabular}{|c|c|c|}
\hline Received: March 2019 & Accepted: Mei 2019 & Published: Juni 2019 \\
\hline \multicolumn{2}{|c|}{ Article DOI: http://dx.doi.org/10.24903/ jam.v3i2.505 } \\
\hline
\end{tabular}

\title{
Penyuluhan Kosmetika Aman dan Identifikasi Merkuri dalam Kosmetika
}

\author{
Risa Supriningrum \\ Akademi Farmasi Samarinda \\ risa_akfar@yahoo.com \\ Siti Jubaidah \\ Akademi Farmasi Samarinda \\ ida_mapro13@gmail.com
}

\begin{abstract}
Abstrak
Kosmetik merupakan hal penting dalam kehidupan manusia saat ini, karena kosmetik sudah merupakan kebutuhan dan gaya hidup bagi wanita maupun pria, disegala usia. Banyaknya produk kosmetik yang beredar di pasaran dan ditawarkan di berbagai media, mengharuskan masyarakat berhati-hati dalam menentukan produk kosmetik yang akan digunakan. Generasi milenial merupakan usia produktif banyak menggunakan kosmetika. Tujuan pengabdian masyarakat ini adalah memberikan informasi tentang kosmetika aman dan memberikan pelatihan cara mengidentifikasi merkuri dalam kosmetika .Metode yang digunakan pada pengabdian masyarakat ini adalah penyuluhan yaitu memberikan informasi tentang pengertian, fungsi kosmetika, bahan yang dilarang dan bahan berbahaya yang sering digunakan dalam kosmetika. Selain penyuluhan, siswa diberikan pelatihan tentang langkah cerdas memilih kosmetika dengan melakukan cek Klik , mengidentifikasi sediaan kosmetika secara visual dan mengidentifikasi merkuri dalam kosmetika. Selanjutnya siswa diberikan kuisioner yang dimaksudkan untuk mengetahui pemahaman siswa setelah diberi penyuluhandan pelatihan. Kegiatan dilakukan di Sekolah Menengah Atas Negeri 3 Samarinda. Hasil kuisioner menunjukkan bahwa 98 persen siswa telah memahami bagaimana memilih kosmetika yang aman dan dapat mengidentifiasi kosmetika secara visual dan kosmetika yang mengandung merkuri.
\end{abstract}

Kata kunci: Penyuluhan, pelatihan, kosmetika, SMAN 3 Samarinda 


\section{(A) ABDIMAS \\ https://journal.uwgm.ac.id/index.php/abdimasmahakam}

E-ISSN : 2549-5755

Juni 2019, Vol. 3 No. 02

\section{Pendahuluan}

Kosmetik dapat diartikan sebagai sediaan yang digunakan pada bagian luar dari tubuh manusia. Bagian luar tubuh yang dimaksud diantaranya epidermis, bibir, rambut, kuku, alat kelamin bagian luar, gigi serta membran mukosa di daerah sekitar mulut. Kosmetik memiliki fungsi diantaranya untuk membersihkan bagian luar tubuh, mewangikan bagian luar tubuh, mengubah penampilan serta usaha melindungi ataupun memelihara tubuh . (BPOM, 2016).

Kosmetika merupakan salah satu produk farmasi yang digunakan setiap hari oleh wanita dan pria mulai dari bayi sampai orang dewasa. Salah satu pengguna kosmetika terbanyak adalah anak muda atau generasi milenial. Mereka ingin selalu terlihat cantik atau berpenampilan menarik . Permintaan pasar akan kosmetik terus meningkat, hal ini mendorong berkembangnya industri kosmetika di Indonesia. Sehingga jenis dan merk kosmetika yang beredar di pasar terus meningkat. Badan Pengawas Obat dan Makanan (2016) menyatakan produsen dalam upaya meningkatkan penjualan kosmetiknya melakukan iklan produk di berbagai media. Melalui iklan dapat disampaikan berbagai informasi yang berkaitan dengan keunggulan produk kepada masyarakat.

Kenyataan yang ada saat ini, terdapat pelaku usaha yang tidak mentaati atau tidak mengetahui peraturan dan etika tentang cara mengiklankan produknya. Hal tersebut dapat merugikan konsumen. Selain itu, kosmetika ilegal juga banyak beredar di pasaran.

Mulyawan,dkk (2013) menyatakan banyak produk kosmetika yang beredar di pasaran mengandung bahan berbahaya yang dilarang penggunaannya dalam kosmetika. Bahan berbahaya tersebut umunya ditemukan dalam produk kosmetika pemutih wajah, anti aging. Bahan berbahaya dan bahan yang dilarang penggunaanya dalam kosmetika oleh Badan Pengawas Obat dan Makanan diantaranya adalah merkuri, zat warna K3, merah K.10 (rhodamin), jingga K.I

Kepala Badan POM menyatakan, bahwa selama tahun 2018, terdapat Rp 112 miliar kosmetik ilegal yang ditemukan BPOM RI. Angka tersebut juga termasuk kosmetik yang mengandung bahan dilarang (BD) atau bahan berbahaya (BB). (http://bangka.tribunnews.com,2018)

Balai Besar Pengawas Obat dan Makanan Kota Samarinda, Kalimantan Timur pada bulan Januari 2019 mengungkap praktik pembuatan kosmetik ilegal dengan omzet miliaran rupiah perbulan Pelaku memasarkan produknya dengan memanfaatkan media sosial, serta akun jual beli barang online (https://www.suara.com/news/2019).

Generasi milenial yang akrab dengan dunia media sosial dan akun jual beli barang online merupakan salah satu konsumen pengguna kosmetika yang perlu mendapatkan edukasi tentang cara memilih kosmetika yang aman. Sehingga pada pengabdian masyarakat kali ini, dipilih siswa Sekolah Menengah Atas sebagai peserta penyuluhan dan pelatihan tentang Kosmetika Aman. 


\section{(A) ABDIMAS \\ https://journal.uwgm.ac.id/index.php/abdimasmahakam}

E-ISSN : 2549-5755

Juni 2019, Vol. 3 No. 02

\section{Metode}

Peserta penyuluhan dan pelatihan kosmetika adalah siswa kelas XI Sekolah Menengah Atas Negeri 3 Samarinda. Lokasi sekolah di jalan Juanda, Samarinda Ulu. Semua siswa laki dan perempuan adalah pengguna produk kosmetika dan terkadang membeli produk kosmetika secara online.

Tahapan pelaksanaan kegiatan adalah:

1. Melakukan survey lokasi, mengurus perijinan untuk melakukan kegiatan penyuluhan dan pelatihan di SMAN 3 Samarinda.

2. Menyusun jadwal kegiatan yang disesuaikan dengan jadwal pembelajaran siswa. Kegiatan ini dilakukan 2 (dua) kali.

3. Pelaksanaan penyuluhan dengan materi pengertian kosmetika, bahan yang dilarang (BD) dan bahan berbahaya (BB) yang banyak ditemukan dalam kosmetika, peraturan terkait bahan kosmetika, langkah cerdas memilih kosmetika.

4. Pelatihan mengenali sediaan kosmetika secara visual, mengidentifikasi merkuri dalam kosmetika dan mengaplikasikan langkah cerdas memilih kosmetika dengan melakukan cek Klik (cek kemasan, label, izin edar dan kadaluarsa). Sampel kosmetik yang digunakan adalah beberapa krim pemutih wajah, hand body lotion, sampo yang dijual di pasar malam dan di toko kosmetika.

5. Dilakukan survey terhadap siswa setelah mereka memperoleh penyuluhan dan pelatihan tentang kosmetika . Siswa diminta mengisi form kuisioner yang telah disediakan.

\section{Hasil dan Pembahasan}

Pertemuan pertama, siswa diberikan penyuluhan tentang pengertian , fungsi kosmetika, peraturan terkait kosmetika, bahan dilarang dan bahan berbahaya yang banyak ditemukan dalam kosmetika. Sejauh ini siswa hanya mengetahui yang dimaksud kosmetika adalah sediaan yang biasa digunakan pada wajah, tangan dan kaki, seperti pelembab, alas bedak, bedak, blush on, lipstik, hand body, lulur dan sejenisnya. Sedangkan kosmetika dapat diartikan sebagai sediaan yang hanya digunakan pada bagian luar tubuh, diantaranya berfungsi untuk membersihkan tubuh, memberikan aroma wangi pada tubuh, memperbaiki penampilan, memperbaiki bau badan, juga untuk melindungi atau memelihara tubuh. Sediaan tersebut digunakan pada rambut, kulit, kuku, gigi, membran mukosa sekitar mulut, bibir.

Berdasarkan pengertian tersebut, maka yang termasuk kosmetik, sangat banyak ragamnya, seperti shampo, pewarna rambut, mouth wash, parfum, hand body lotion, lipstik dan lain-lain. 
E-ISSN : 2549-5755

Juni 2019, Vol. 3 No. 02

Foto 1 Penyampaian materi penyuluhan Kosmetika aman

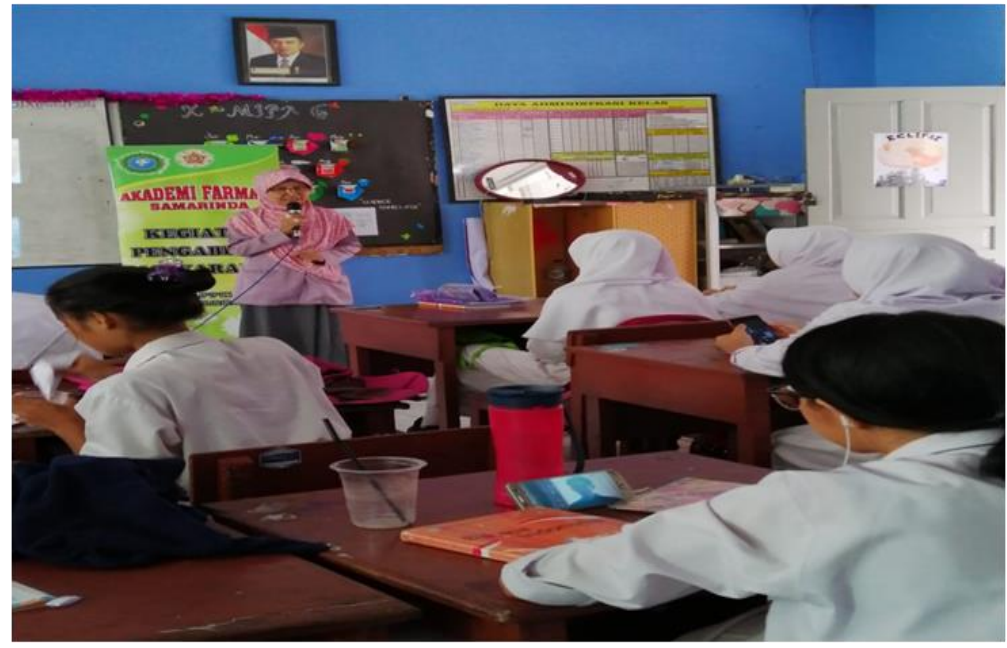

Foto 2 Cara identifikasi merkuri dalam kosmetika

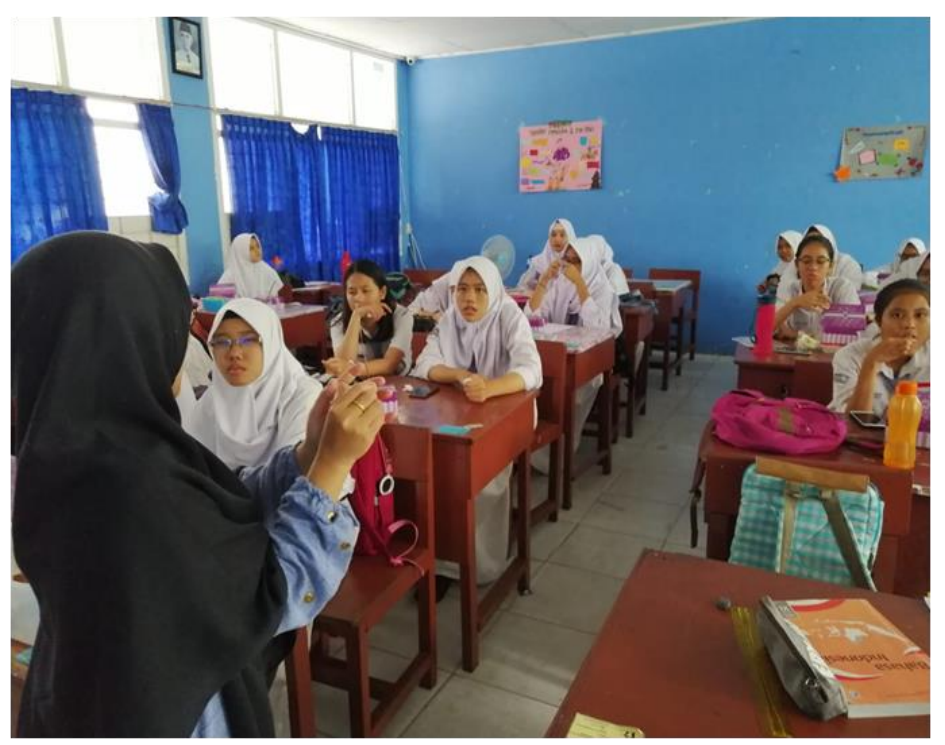




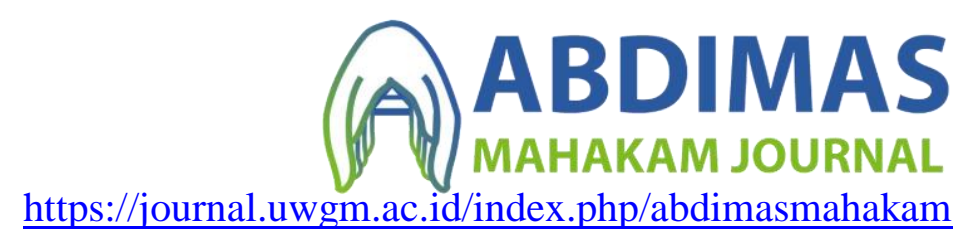

E-ISSN : 2549-5755

Juni 2019, Vol. 3 No. 02

Foto 3 Siswa melakukan cek "KLIK" (Kemasan, label, ijin edar dan kadaluarsa kosmetik)

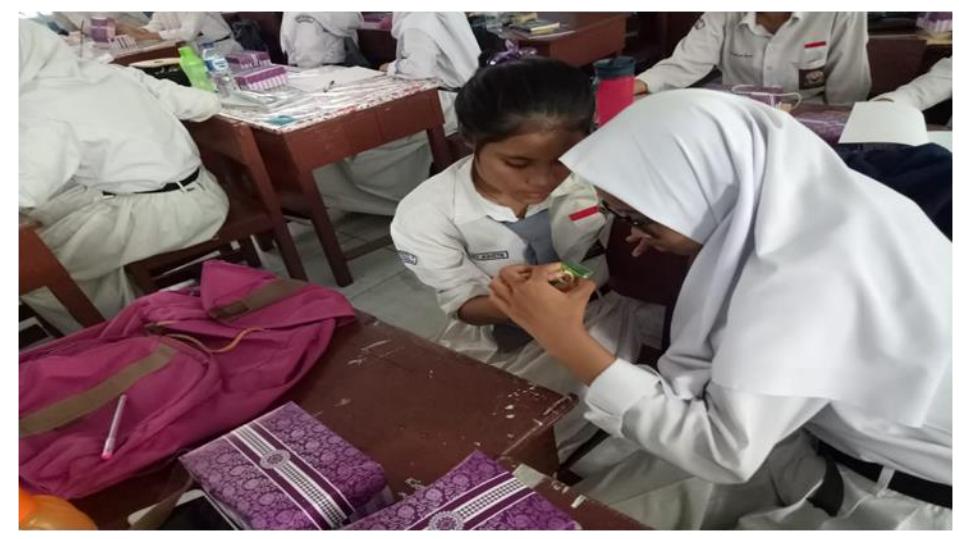

Siswa harus berhati-hati saat akan membeli kosmetika, terutama dari pasar malam dan online shop, karena produk yang dijual pada umumnya tidak memiliki izin edar dan diproduksi oleh orang yang tidak memiliki pengetahuan tentang pembuatan kosmetika yang baik dan benar. . Sehingga formula dan takarannya pun tidak dapat dipertanggungjawabkan. Begitu juga kosmetika yang dijual di pasar malam, karena dari hasil pengamatan, ternyata sampel yang dibeli di pasar malam tidak memiliki izin edar dan ketentuan lain seperti yang dipersyaratkan oleh Badan Pengawas Obat dan Makanan. Selain hal tersebut, pengamatan secara visual atau organoleptik terhadap sampel menunjukan, bahwa kosmetika ilegal memiliki konsistensi lengket seperti permen karet, tidak homogen, warna kusam. Uji adanya merkuri pada sampel krim pemutih dilakukan menggunakan metode uji kawat tembaga. Hasil uji merkuri menunjukkan krim pemutih yang diambil sebagai sampel dan diperoleh dari pasar malam menunjukkan positif mengandung merkuri.

Berdasarkan hasil kuisioner, ternyata 98 persen siswa telah memahami tentang kosmetika dan bagaimana cara memilih kosmetika yang aman. Harapannya, dengan bertambahnya pemahaman siswa tentang kosmetika, maka mereka dapat membagi pengetahuannya kepada keluarga atau masyarakat sekitarnya.

\section{Simpulan dan rekomendasi}

Simpulan yang di dapat dari Penyuluhan tersebut adalah Siswa kelas XI IPA 6 SMA Negeri 3, Samarinda bertambah pengetahuannya tentang kosmetika dan bagaimana cara memilih kosmetika yang aman serta Siswa juga dapat mengenali kosmetika yang ilegal secara visual atau organoleptis. Rekomendasi yang dapat di berikan agar Siswa lebih berhati-hati dalam memilih kosmetik setelah mendapatkan pengetahuan dari penyuluhan tersebut. 


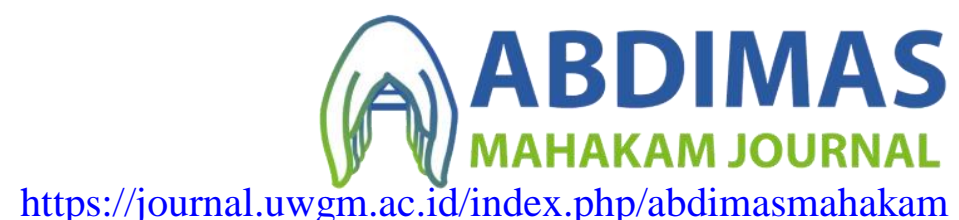

E-ISSN : 2549-5755

Juni 2019, Vol. 3 No. 02

\section{Daftar Pustaka}

Muliyawan, Dewi ., Suriana, Neti. 2013. A-Z Tentang Kosmetik. Jakarta: PT Elex Media Komputindo

http://bangka.tribunnews.com/2018.bpom-tarik-13-produk-kosmetik-dari-peredaran-ini-bahayanyabagi-kesehatan-kulit

https://www.suara.com/news/2019.Kosmetika Pabrik Kosmetik Ilegal Beromzet Rp 80 Juta Sehari Terungkap di Samarinda

Badan Pengawas Obat dan Makanan, 2016. Frequently Asked Question, Iklan Kosmetika. Jakarta: BPOM 